\title{
La lettre du Collège de France
}

39 | mars 2015

La Lettre $n^{\circ} 39$

\section{La guerre a bouleversé l'amour}

\section{Michelle Perrot}

\section{(2) OpenEdition}

Journals

Édition électronique

URL : https://journals.openedition.org/lettre-cdf/1942

DOI : 10.4000/lettre-cdf.1942

ISSN : 2109-9219

Traduction(s) :

The War Transformed Love - URL : https://journals.openedition.org/lettre-cdf/2197 [en]

\section{Éditeur}

Collège de France

\section{Édition imprimée}

Date de publication : 1 mars 2015

Pagination : 14-15

ISSN : 1628-2329

\section{Référence électronique}

Michelle Perrot, «La guerre a bouleversé l'amour », La lettre du Collège de France [En ligne], 39 | mars

2015, mis en ligne le 01 août 2015, consulté le 17 août 2022. URL : http://journals.openedition.org/ lettre-cdf/1942 ; DOI : https://doi.org/10.4000/lettre-cdf.1942 


\section{La guerre a bouleversé l'amour}

\author{
" La guerre a bouleversé l'amour ", écrit Blaise \\ Cendrars, qui a lui-même vécu cette expérience \\ dramatique. Mais encore? Comment les hommes \\ et les femmes ont-ils vécu la Grande Guerre, \\ non seulement dans leurs rapports affectifs, \\ amoureux, sexuels, mais plus largement dans \\ tout ce qui tisse leurs relations : la vie familiale, \\ l'intimité, le public et le privé, le travail, l'écriture, \\ l'image, le corps et l'âme?
}

La guerre, c'est d'abord l'ordre des sexes triomphant : hommes au front, dans la virilité du combat; femmes à l'arrière, les aidant, les soignant, les remplaçant, les attendant. Elles sont confortées dans leur rôle traditionnel et maternel d'auxiliaires et d'infirmières. L'infirmière voilée de blanc : voilà l'incarnation, quasi religieuse, de la féminité. Pour les déclinistes de la Belle Époque, il y a une moralité de la guerre purificatrice, régénératrice. "La guerre, hygiène du monde », avaient proclamé les futuristes. Mais la guerre dure. Elle a des effets parfois inattendus.

Elle a d'abord des effets démographiques. Le recul du taux de nuptialité et de natalité aggrave la crise démographique qui s'esquissait. Le nombre des mariages, souvent différés, a reculé, en dépit de nombreuses régularisations d'unions effectuées à la hâte, surtout dans les milieux populaires où le concubinage était fréquent. Cela ne compense pas. Les formalités ont été pourtant allégées; on a instauré (loi de 1915) le mariage par procuration qui permet de s'épouser "à distance "; mais son manque de poésie a provoqué son rapide déclin au profit des permissions, qui permettaient de brèves épousailles. Mais pourquoi s'épouser devant tant d'incertitudes?

Car la séparation est brutale (plus de 3 millions d'hommes mobilisés, beaucoup plus au cours de la guerre) et totalement inédite dans cette ampleur. Elle désorganise le foyer, le travail, l'intimité, les rôles. On pare au plus pressé. Puis on s'installe dans la guerre. On tente de préserver un lien qui se révèle indispensable. La correspondance joue ici un rôle majeur. D'une certaine manière, elle banalise la guerre, elle accommode le tragique et le rend acceptable. Non que les soldats taisent la guerre et ses opérations. Obligés à la discrétion sur les lieux, ils décrivent, et de plus en plus, les horreurs du front; la boue, les poux, les promiscuités, les bombardements, le sang, les cadavres. Au début, ils se veulent rassurants. Les « boches » seront vaincus, c'est certain. Puis le doute s'insinue; ces gens-là sont plus coriaces qu'on ne croyait. II devient impossible de taire la résistance de l'ennemi et la brutalité de la guerre. Mais les femmes comprennent-elles? Entendent-elles? Le quotidien est plus dicible et remplit des lettres d'une répétition rassurante. Les soldats parlent de la nourriture, des colis, si bienvenus, du couchage, aléatoire, des camarades. Ils s'enquièrent des travaux des champs, de la marche des affaires, de la conduite des enfants. Contraints à déléguer leur rôle, ils voudraient continuer à diriger par procuration et dispensent à leurs épouses des conseils, de fermeté surtout pour l'éducation des enfants qu'ils redoutent toujours insuffisamment virile sans eux. Ils se sentent dépossédés d'une paternité dont ils mesurent l'importance dans leur vie.

Ils parlent aussi de sentiment. Par-dessus tout, ils redoutent d'être quittés, trompés et voient dans chaque retard de courrier une marque d'abandon. Même Louis Pergaud, si sûr de l'amour de Delphine, s'alarme et morigène. "N'as-tu pas le temps de m'écrire? ». La sexualité est plus difficile à dire. Elle s'exprime différemment selon les milieux et les capacités d'écriture, le degré d'intimité antérieur. Louis Pergaud y excelle et l'expression du désir se fait chez lui de plus en plus vive. Pudique, il parle d'abord de " baisers sur tes beaux yeux ". II parle d'étreintes « très fortes » et « répétées ». II demande « un baiser passionné et chaud comme tu sais me les donner et dont j'ai une si vive nostalgie maintenant à toute heure... » «Quelles étreintes je te promets, ma gamine bien chère, et avec quelle ardeur je te caresserai, je te cajolerai. Et puis, peut-être aurons-nous enfin le bébé que nous espérons ", écrit-il en février 1915. II sera tué un mois plus tard. Pergaud n'est pas le seul à écrire ainsi son amour charnel. Clémentine Vidal-Naquet ${ }^{1}$ donne d'autres exemples de cette « inflation sentimentale » et érotique, née du manque, de l'absence et que comble dans une certaine mesure la remémoration (de la chambre, du lit) et l'anticipation d'un bonheur escompté. Elle n'était pas seulement - et c'est très neuf tant la pudeur clôt les lèvres des femmes - le fait des hommes, mais des épouses aussi. " II y a des choses qu'on fait et dont on ne parle pas, et justement ce sont les meilleures », dit l'une ${ }^{2}$. Paradoxalement (mais est-ce si paradoxal ?), la guerre a stimulé le désir d'intimité et de plaisir partagé. Elle a érotisé l'amour conjugal à l'égal des autres formes de sexualité, poursuivant une évolution amorcée avant guerre, comme l'a montré Alain Corbin ${ }^{3}$.

Louis Pergaud réprouve le puritanisme de l'armée. Dans son secteur, le commandement a interdit les visites féminines. II souligne cette montée d'un érotisme latent qui s'exprime dans les conversations grivoises des officiers (dans l'artillerie notamment) et dans les propos et correspondances des poilus. Situation qu'il 


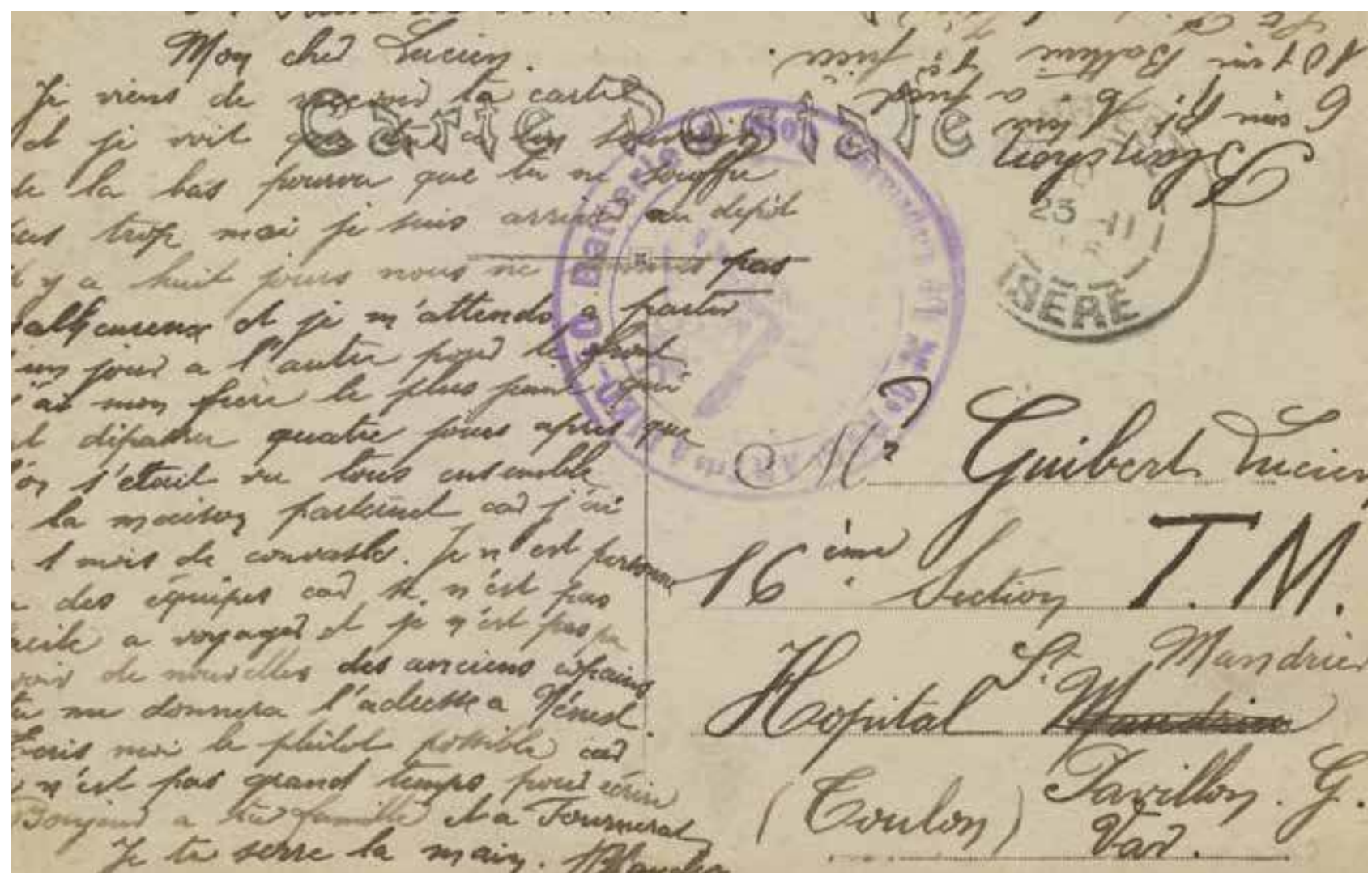

Carte postale d'un poilu, 1916, DR

décrit en termes assez crus dans une lettre à un ami (Marcel Martinet, 10 mars 1915) : " Si jamais on entrait en Allemagne, je crois qu'il serait bien difficile d'empêcher les poilus de rendre aux Gretchen le sperme que leurs cousins ou fiancés ont semé chez nous ». Allusion claire au viol pratiqué par les envahisseurs, qui a engendré plusieurs milliers d'enfants naturels ${ }^{4}$ et qui légitimerait une revanche du même ordre. Le corps des femmes n'a pas cessé d'être un enjeu, réel et symbolique, des luttes nationales. Un terrain de guerre, un légitime butin.

La guerre n'a pas moralisé la société, comme l'escomptaient les déclinistes. La misère sexuelle ${ }^{5}$ a entraîné le recours à la prostitution, clandestine, et organisée tardivement (en 1918) dans des « bordels de campagne ", dont certains officiers (ainsi le Général Mordacq) auraient voulu faire des centres de réglementarisme hygiénique et prophylactique inspirés de modèles germaniques et destinés à prévenir le péril vénérien, en plein essor. La guerre a contribué à normaliser et à médicaliser la sexualité. Plus largement, «l'investissement politique massif des médecins en cette grande Guerre pose les bases d'un totalitarisme médical ${ }^{6}{ }$. La guerre a renforcé le rôle de l'État dans tous les domaines, y compris celui du privé. En retour, elle a provoqué une conscience avivée du désir de l'intimité et d'un espace, d'une vie à soi. Selon un processus classique, l'accroissement des contrôles nourrit le sens de l'individualité.

Mais la guerre a eu bien d'autres effets sur les rapports de sexes, notamment dans le domaine du travail. À la terre, dans les usines, voire à la direction des entreprises, les femmes ont "remplacé » les hommes. Elles ont exercé de nouvelles responsabilités, manié l'argent, pris des décisions, quitté l'espace du foyer, fait d'autres rencontres. Les ouvrières mariées, qui s'étaient vues, en 1907, reconnaître enfin le droit de percevoir directement leur salaire, disposaient désormais librement de rémunérations plus élevées. Dans l'espace taylorisé de l'usine, dont elles découvraient la discipline, mais aussi les avantages ${ }^{7}$, elles n'hésitaient plus à s'associer, voire à revendiquer. En 1917, « munitionnettes » et midinettes défilaient ensemble dans les rues de Paris pour faire valoir leurs droits. Les femmes avaient gagné en autonomie, en indépendance, parfois en liberté amoureuse. Certains s'en alarmaient qui déploraient le luxe des « bas de soie » des " profiteuses de guerre ». Un profit très exagéré, car ces femmes devaient gérer un quotidien difficile, assumer seules les charges familiales (enfants, parents âgés parfois) et les angoisses du lendemain. Mais ces fantasmes hantaient les tranchées et provoquaient l'anxiété des mâles esseulés. La guerre a pu resserrer les couples. Elle a aussi éloigné les sexes.

Extraits de la communication prononcée par Michelle PERROT

(1) Clémentine Vidal-Naquet, Couples dans la grande guerre, Paris, Les Belles Lettres, 2014, p. 325 sq. (2) Ib., p. 360. (3) Alain Corbin, L'Harmonie des plaisirs. Les manières de jouir du siècle des Lumières à l'avènement de la sexologie, Paris, Perrin, 2008. (4) cf. Stéphane Audoin-Rouzeau, L'Enfant de l'ennemi, Paris, Aubier, 1995; Raphaëlle Branche et Fabrice Virgili (dir.), Viols en temps de guerre, Payot, 2011. (5) Jean-Yves Le Naour précise tous les aspects de cette histoire dans Misères et tourments de la chair (Paris, Aubier, 2002). (6) Cf. Jean-Yves Le Naour, op.cit., p.217. (7) Dans les usines d'armement, notamment sous limpulsion d'Albert Thomas, de la Guerre, on avait institué des chambres d'allaitement et instauré des surintendantes de la Guerre, on avait institué des chambres d'allaitement et insta
d'usine chargées de veiller aux respects des conditions de travail.

Retrouvez en ligne l'intégralité de cette intervention sur le site Internet du Collège de France : www.college-de-france.fr/site/colloque-2014/ symposium-2014-10-17-17h00.htm
Michelle PERROT

Université Paris 7

Diderot 